\title{
Evaluation of a Design Thinking MOOC: A Preliminary Investigation
}

\author{
Tze Ying Sim \\ Centre for American Education \\ School of Interdisciplinary Studies \\ Sunway University \\ Bandar Sunway, Malaysia \\ tzeyings@sunway.edu.my
}

\author{
Sian Lun Lau \\ Department of Computing and Information System \\ School of Science and Technology \\ Sunway University \\ Bandar Sunway, Malaysia \\ sianlunl@sunway.edu.my
}

\begin{abstract}
Design thinking courses are commonly conducted in a workshop manner. There are courses delivering design thinking using the massive open online course format. However, the findings on the MOOC platform reveals that the platform lacks interactivity and collaboration between learners. This research proposes additional steps in the evaluation of MOOC content through the assessment submissions and feedback by participants. The additional triangulation of "assessment and feedback" and evaluation complement the common method of independent review of the content. The two additional methods provide more information on the area that needs to be improved. Other factors like motivation for completion and the effectiveness of the content delivered online will also be discussed. The second focus is to identify the impact of online workshops to support the collaboration and interaction aspects. The research studies the utilization of such features in the MOOC platform. This is followed by future work following this research.
\end{abstract}

Index Terms-MOOC, Design Thinking, Online Workshop, Electronic Learning, Learning Management Systems

\section{INTRODUCTION}

A Massive Open Online Course (MOOC) is an online course that is made available to the masses for enrolment for free or with a fee. The platform to host the courses are known as MOOC platforms. MOOC platforms include Coursera, Udemy, MIT edX, Udacity, Canvas, Khan Academy, and OpenLearn. There are two types of MOOCs. During the earlier phases of MOOCs, they are offered as free courses available for the masses. This category of MOOCs is known as the cMOOCs. Another category, the xMOOCs, focuses on the completion of a specific course normally offered by a higher education institution and is made available to the institution's students or charged a fee to an outsider.

Design thinking is a set of methodologies to assist in product creation, focusing very much on the customer perspective as well as other stakeholders [1]. The basic steps of design thinking include empathize, define, ideate, prototype, and test. It does not necessarily happen linearly. Each step can be revisited as required. Among standard tools used for design thinking activities are post-it, modeling clay, markers, crayons, strings, and different tools commonly used for building a prototype and gathering ideas.

It is common for a design thinking workshop to be conducted in a face-to-face manner. If one would like to move the workshop contents online, i.e. to offer a design thinking workshop as a MOOC course, the question remains - will an online design thinking workshop still deliver expected outcomes as compared to a face-to-face variant? This question is valid as a design thinking workshop is typically done in an experiential manner. Hence, when substantial face-toface activities are absent, one would expect the learning outcome may be affected. In particular, in 2020, when Covid19 pandemic indirectly "forced" courses to be moved to online and remote delivery, the answer to this question will be timely.

This research looks at the criteria of evaluating a Design Thinking course that is conducted online using a MOOC platform. The evaluation has two objectives:

1) Determining the impact and contribution of the various factors in evaluation the MOOC content

2) Determining the impact of integrating a workshop to complement the online course

Firstly, the European Quality Reference Framework provided a very comprehensive view of the dimensions to evaluate the MOOCs. However, most of the evaluation is designed to assess the MOOC before the platform is deployed. The evaluation of the content is as per the content itself. This research will also evaluate the content based on assessment submissions by the students. The two findings will be compared to the evaluation by the students.

Secondly, online courses for design thinking are lack of interaction and collaboration between the instructor and students; and between students and students [2]. One of the suggestions is to have a social collaborative platform on the MOOC platform. The research will evaluate the behavior of the students on the platform and the impact of the opportunity to work in groups for the final challenge. The feedback from the students for the online workshop will also be presented.

\section{LITERATURE REVIEW}

\section{A. Evaluation of MOOC platforms and MOOCs}

Marchisio and Sachet [3] analyzed the items to determine the quality of a massive open online course (MOOC) platform through the courses enrolled. The framework consists of three dimensions: 1) Phases - Analysis, Design, Implementation; 2) 
Perspective - Pedagogical, Technological and Strategic; and 3) Roles - Designer, Facilitator, Provider. The checklist for item analysis is based on the OpenupEd "Quality of the Design of MOOC." Gamage, Perera, and Fernando [2] also evaluated MOOC using two different sets of tools. The first tool consists of the following criteria user interface, assessment, video content, learning, social engagement, instructional design. The second set of tool has ten criteria, namely, interaction, collaboration, motivation, network of opportunities and future directions, pedagogy, content, assessment, usability, technology, and support for learners. The findings were MOOC platforms lack interactivity between learners and opportunity for collaboration within a social structure [2]. Suggestions for MOOC platform development include 1) Scaffolding interaction designs to engage with other learners, 2) Open collaborative group selection 3) Student instructor interaction, 4) Co-creation of content with students, 5) Creation of open learning communities.

The European Union Quality Reference Framework (MOOQ, 2018) covers three dimensions: 1) the phases and processes, 2) the perspectives, and 3) the roles. The phases and processes are further divided into five areas 1) analysis, 2) design, 3) implementation, 4) realization, and 5) evaluation. Each of the processes may have between one to three perspectives: 1) pedagogical, 2) technological, 3) strategic. Each of the phases involves different roles, namely, 1) designer, 2) facilitator, and 3) provider. The framework provided a comprehensive checklist of items for evaluation.

\section{B. MOOCS and Design Thinking}

Wrigley, Mosely, and Tomitsch [4] compared a range of courses for MOOCs for Design Thinking Education. They evaluated "thirty-five design thinking online courses delivered across twelve learning platform ... (the content were categorized in seven categories, namely 1) Introductory, 2) Start-ups; 3) Leadership and Implementation; 4) Human-centred Design; 5) Social Innovation; 6) Design Education; and 7) Business Strategy" (pg. 282) [4]. The conclusion from the research is that the MOOC platform can deliver the foundation for the subject domain and serve as the prerequisite to progress to higher-level subjects. However, face-to-face delivery and interaction are critical for effective transmission of the design thinking theory and the skillsets development of the students. The online design thinking courses have a disparity in terms of the targeted learning outcome. Therefore, Wrigley and team proposed for the online Design Thinking courses to only cover level one of the educational ladders and have levels four to five delivered in a face-to-face format.

Dosi, Rosati, and Vignoli [5] developed a set of questionnaires to measure the development of the design thinking mindset. It has 71 items and is based on 22 constructs.

There was much work done in the area of design thinking, including integrating them into specific subjects. For example, Business, Arts and STEM [6], Software Engineering [7]-[9], Human Computer Interface [10], Game Design [11] and Media Education [12]. Very often, workshops were also conducted to disseminate and evaluate the skills acquired [13], [14]. The implementation of design thinking is wide and very often delivered in a face-to-face format.

\section{Methodology}

\section{A. Course Content}

The course is hosted on a MOOC platform. The objective of the course is to present the design thinking methodology to students who have not been exposed to it. According to Wrigley, Mosely, and Tomitsch, this will be categorized as an introductory course [4]. At the end of the course, the students are expected to use the design thinking method to solve problems. The syllabus is divided into three phases: 1) Discover, 2) Explore, and 3) Solve. The subtopics are depicted in Fig. 1.

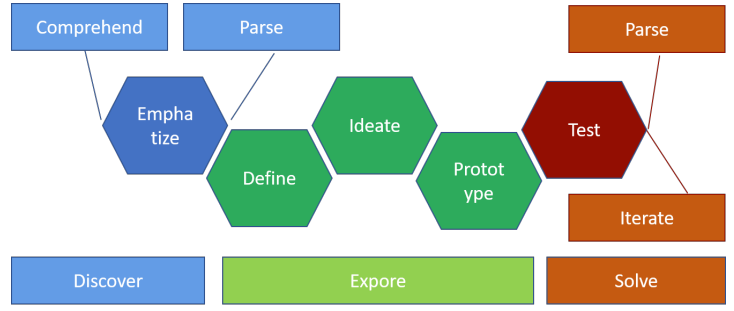

Fig. 1. Content of MOOC as compared to original Design Thinking phases.

The MOOC platform allows the students to interact with other students and the instructor via comments on the postings and the chat function. During the first activity, the students are required to introduce themselves, ask a question, and answer at least one question posed by other participants. They would need to identify an area that they would like to solve using the design thinking approach. The content consists of case studies, images, videos, and powerpoint templates to guide the students to think through each phase's requirements.

\section{B. Assessment and Evaluation}

1) MOOC Assessment: At the end of every phase, each student is required to submit the outcome of the different activities. As to increase the collaboration and interaction between the students, they will then need to work together to solve the given problem at the end of the course. The instruction given to the students are as below:

1) Form a group of 4 or 5 students. Make sure that you have at least 1-2 participants with a programming background in your group as they will be able to provide you good inputs and guidance for this challenge.

2) Discuss and assign a group leader and group name for your group.

3) Your group leader must create a group space in the platform. This group space provides a space for you to discuss, collaborate, and build solutions together.

4) Once you are done and understand the challenge above, go to your own Group Dashboard

5) Think and discuss with your teams on what you understand on what the Challenge, Problem Statement and 
Final Product which are given above. Come up with a summary in your own words of the Challenge, Problem Statement, and Final Product.

6) Post your summary in your Group Dashboard and let your other teammates give their feedback on your submission. You need at least one person from a programming background to comment and give their feedback on your post.

7) Based on what you have learned, propose solutions for the given challenge.

8) Submit the artifact and pitch in your respective group dashboard. Have fun!

The group work is not graded. Students were informed that the group work would serve as a practice ground for their final design thinking challenge.

2) Final design thinking challenge: The final design thinking challenge was initially planned to be a face-to-face challenge and had to be converted to be an online workshop due to the Covid-19 situation. The students were given the following problem statement.

During a crisis like Covid-19, physical teaching and learning are no longer possible and need to take a new form. Propose a teaching and learning solution that is adaptable for a specific target audience according to your customer persona. As time is limited, you are advised to choose a customer persona that you are most familiar and propose the solution accordingly.

The students are required to pitch the solution by the end of the day. The online workshop took place between 9 am and 5 $\mathrm{pm}$. The online workshop was conducted using the university's learn management system. The pitching session is evaluated by panels from Petronas and Sunway University.

\section{Participants Recruitment}

There were two groups of students who took part in this project. They were divided into two groups, with one group started earlier and thus having more time to complete the work and another group at a later time. Each group of the students was recruited via an announcement on the student learn management system, and the participation is voluntary.

The students registered themselves via a Google Form link that was included on the recruitment poster. They were required to pay a "participation deposit" of RM30 to secure a place, and the deposit will be refunded if they participated in the program. However, if they did not participate in the research at all, the deposit will be forfeited. The student will be remunerated with RM40 for completing the MOOC and another RM30 for participating in the final challenge. The researcher also coupled this project with another Hackathon selection that would take place in Finland in May.

A project briefing was conducted before the students participate in the course. The project briefing explains the objective of the research project, the expectations, and the payment. A copy of the briefing presentation was sent to the participants after the project briefing.
1) Changes due to Covid-19: The final face-to-face challenge was scheduled for 18th March 2020. That was the date where Malaysia will enforcement the movement control order (MCO) due to the pandemic, Covid-19, situation in Malaysia. The announcement was made on 16th March 2020. Therefore, the participants were informed on the 16th March 2020 on the deferment of the face-to-face workshop. The final face-toface challenge was converted to be an online challenge and was conducted on 6th June 2020. The Hackathon project with Finland was also postponed due to the Covid-19 situation.

\section{RESULTS AND DISCUSSION}

\section{A. Impact and factors of different tools in evaluating the MOOC content}

The effectiveness of the content is evaluated in three different ways:

1) independent reviewer

2) assessments submitted by the students

3) the students' feedback

The three factors of evaluation are often conducted for a subject; namely, 1) through independent review of auditing agency or external examiners, 2) the performance of students for subjects or coursework, and 3) evaluation provided by students. Each component will provide further insights into the course. The research will evaluate the role of each of these tools and the relationship between them.

1) Independent Reviewer: The evaluation tools used by the independent reviewer is similar to the first set of tools proposed by Gamage [2]. Please see Fig. 2 for more details.

\begin{tabular}{|l|l|l|}
\hline Criteria & Evaluation & Remarks \\
\hline User interface & Very Good & Clean and not cluttered \\
\hline Assessment & Good & $\begin{array}{l}\text { Detailed template is provided for the students' } \\
\text { submission }\end{array}$ \\
\hline Video Content & Average & Only available for the prototyping phase \\
\hline Learning & Good & $\begin{array}{l}\text { Covered all the aspects of design thinking with } \\
\text { sufficient depth for introductory level }\end{array}$ \\
\hline Social Engagement & Good & $\begin{array}{l}\text { There are opportunities for students to comments } \\
\text { each other work and chat with each other }\end{array}$ \\
\hline Instructional Design & Very Good & $\begin{array}{l}\text { Sufficient interesting activities to engage the } \\
\text { audience }\end{array}$ \\
\hline
\end{tabular}

Fig. 2. Feedback by indepent reviewer

However, it is interesting to note that the content was not evenly distributed. Some steps are heavier than others, for example, the define and ideate steps, where five submissions are required. The prototyping phase has many readings and videos to explain the different ways of prototyping, with only one submission. The empathize phase and the pitching phase were leaner, with only one or two submissions required and no other activities. The differences in terms of content and submission is not much of an issue as long as the learning outcome is met. The information and expectations of each module are clear.

2) Assessments submitted by the students: Using the Likert scale of 1 to 5, the submissions of the students were evaluated. 1 point is awarded for Unacceptable, 2 for Below Expectation, 3 for Meeting Expectations, 4 for Exceed, and 5 for Outstanding. As the students followed the instructions given, 
the average score is at 3 - Meeting Expectations. The score 4 - Exceed is awarded when the student elaborated in great detail on what is required. No students achieved the score 5 - Outstanding. The score 2 - Below expectation is awarded when the submission is less than expectation or did not fulfill all the requirements. For example, for visual unpacking, the students mentioned the primary and secondary data source as literature and interviewing friends. However, they fail to specify what criteria of literature or friends are directly related to the proposed product.

TABLE I

RESULT FOR THE DISCOVER PHASE

\begin{tabular}{|c|c|c|}
\hline Discover Phase & Activities & Average Score \\
\hline Comprehend & KWL & 3.0 \\
Empathize & Empathy Triangle & 3.3 \\
Empathize & Empathy Studies & 3.5 \\
Parse & Visual Unpacking & 2.6 \\
Parse & Analysing the Data & 2.9 \\
\hline
\end{tabular}

As shown in Table I, for the discover phase, the best component was "empathy studies and empathy triangle." The activities for the "empathy triangle" are simple exercises where students need to ask questions on "ask and observe," "try and do," and "ask and listen." "Empathy studies" require the students to specify the source of primary and secondary data. The students were able to relate the product to the source of their studies. Only a few students were general, in terms of collecting their data from google forms without mentioning the specific audience. The "visual unpacking" requires the students to analyze their data collected and find important information from the data. The answer by the students who missed the mark did not have a clear indication of the product that they are trying to develop, or the statements are very general. For example, "need to get to the root of the problem."

TABLE II

RESULT FOR THE EXPLORE PHASE

\begin{tabular}{|c|c|c|}
\hline Explore Phase & Activities & Average Score \\
\hline Define & Building Personalities & 3.2 \\
Define & Experience Journey map & 3.8 \\
Ideate & How Might We & 3.0 \\
Ideate & SCAMPER Tool & 2.6 \\
Ideate & Impact vs effort matrix & 2.8 \\
Ideate & Stakeholder Analysis & 3.0 \\
Ideate & Concept Poster & 3.2 \\
Prototype & Prototyping ideas & 2.7 \\
Prototype & Review a Prototype & 2.3 \\
\hline
\end{tabular}

For the "explore phase" (see Table ??, the best score is for the "Experience journey map." The "Experience journey map" requires the student to chart through their day. The student did a good job in the elaboration. The grader assumed that the opportunity stated will be addressed by the product the student is going to introduce. However, that is not the case, as the concept poster reveals a different concept. The "review a prototype" activity received the lowest score at 2.3 because many students did not provide specific comments to the prototype of other students.

TABLE III

RESULT FOR THE EXPLORE PHASE

\begin{tabular}{|c|c|c|}
\hline Solving Phase & Activities & Average Score \\
Empathy 2 & Feedback Grid & 2.9 \\
Iterate & Iterate & 3.0 \\
Pitch & Pitching & 2.5 \\
\hline
\end{tabular}

For the "solving phase" (see Table III), the students "imagined" what modifications may be required of their product. The students provided assumptions and situations that may cause them to make changes to their products. The "pitching" activity see that most of the students followed exactly the instruction.

Three conclusions can be drawn from the students' submission:

1) The students understood the requirements for each of the steps and the individual activities in it. The students can provide the details and the scenario required as per the examples given. Therefore, the examples and information are sufficient for the students to replicate the information needed.

2) The assessment of the students' work concluded that the submission for each activity are not necessarily related to each other and building towards one final product. Out of the 29 students, $8(28 \%)$ students had no clear continuity from one activity to the other, $3(10 \%)$ students have at least two main ideas in the submissions, while connectivity can be drawn between the activities for the other $18(62 \%)$ students. A potential improvement is to have clearer instruction that the activities are all linked to each other.

3) Even though the MOOC platform provided interaction opportunity and the activities include interaction; students did not respond to these activities. The lowestperforming activity was the review of the prototype, at 2.3, where most of the students did not provide concrete feedback to their peers. The students do not comment on the work of peers apart from a few stating "Good Job" or "Congratulations."

3) evaluation and feedback provided by the students: Feedback on the course content was conducted upon completion of the course. Out of the forty students who initially started with the project, one student did not attempt the course; another 13 completed part of the course and another 26 completed the whole course. Twenty-five students responded to the final survey upon completion.

The MOOC content evaluation shows that the students are very satisfied with the content and are clear concerning the requirement of the course The "Before and After" comparison shows that the students' understanding of the design thinking relevance and application improved after the course. They are also able to use the tools as required. The students provided the following feedback concerning the content. 


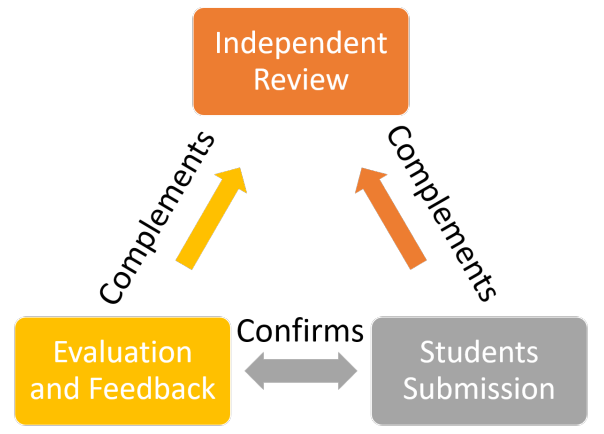

Fig. 3. Evaluation Triangle

- 13 students are interested to learn further on skills that can develop their problem solving and design thinking skills

- 4 students requested more case studies as examples

- 4 students request more information concerning the prototyping and pitching phase

- 2 students mentioned that the work conducted is a silo and not much interaction within the platform with other students

- 1 student each requesting for learning more about evaluating users and using the "How Might We" questions

\section{B. Integrating a workshop to an online course}

One of the research gaps is the lack of social collaboration and interaction on a MOOC platform. This was also highlighted by students in the feedback. The online workshops provided an opportunity for interaction before closing the project.

From the findings of the judges, the students are able to apply the design thinking methods to develop a new product. However, the missing components include conducting a real survey to gather input from the user, and therefore, no actual data were analyzed. This is consistent with the findings from the students' assessment submission.

Next, online collaboration between members of the groups was observed. Seven groups participated in the online workshop. Five groups discussed using audio, with four groups using the same system as the online workshop and another group using a separate tool. Two other groups typed their discussion; the facilitator did remind the students that they can use the audio feature to facilitate the discussion. One group finally used the audio feature in the afternoon, while another group typed all the way!

1) feedback after online workshop: Out of the twenty-six students who participated, most of them joined the workshop because of their interest in learning. This is followed by four students who are interested in the opportunity for innovation and thinking out of the box that design thinking provides. Two students joined the final workshop as not to disappoint their group members. The remaining four students joined each for a particular reason. Please see Fig.4.

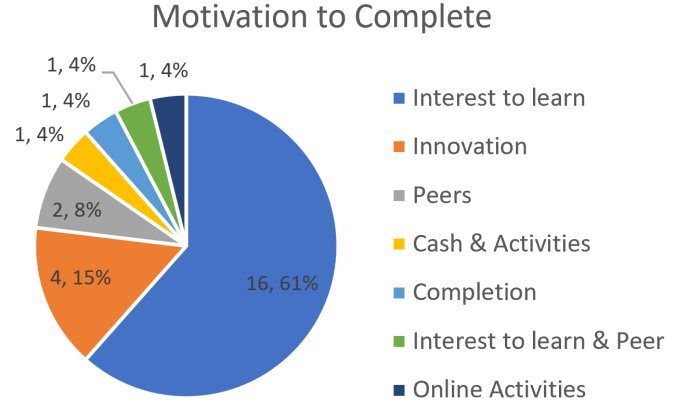

Fig. 4. Motivation for completion

Contrary to the researchers' expectation where remuneration will be the motivation for completion, only one student completed the whole project due to the remuneration. Most of the participants who completed the activity are due to the opportunity to learn, innovation and not wanting to disappoint their group members. Therefore, the social interaction of the online workshop did motivate three participants to complete to project.

The participants provided feedback on online collaboration that was later categorized by the researcher. The highest category was Good, at $46 \%$. Comments that were included in this category are "Good", "Communicate Well". The secondhighest category is Average at 27\%. Comments in this category include "Can be better but do-able", "... teamwork was peaceful and cooperative...", "voice communication is needed to have smooth collaboration." $16 \%$ of the students graded their online collaboration experience negatively. The reason for this is the difficulty to clarify their opinion; the group members are very quiet (even in WhatsApp chat) and device issue.

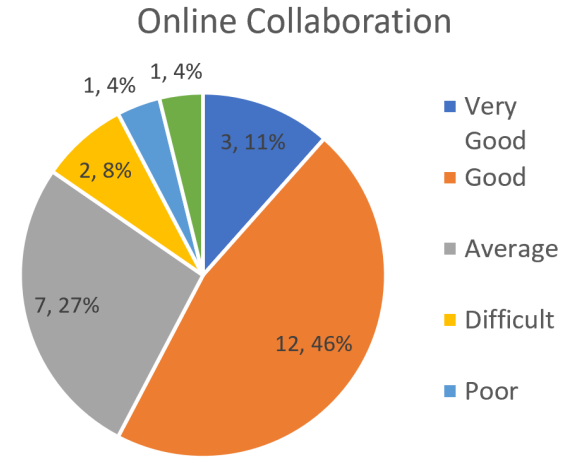

Fig. 5. Comments on Face to Face (F2F) vs. Online workshop

The final questions concerning online workshop was "What would the main difference by having an online workshop as compared to a face to face workshop?" All the students who had "Poor" collaboration in the previous question responded with a "Face to Face Positive" or "Online negative" answer. All "Face to Face Positive" feedback revolves around easier and more positive communication for a face-to-face 
session. The only "Face to Face Negative" comment also revolves around communication - and that is, face-to-face communication is more difficult for a shy person! The main concerns in the "Online Negative" category revolve around the difficulty of communication and internet issues. "Online Positive" comments include the opportunity to practice selfdiscipline, flexibility in location, and the availability of the information uploaded or discussed online.

2) Design Thinking Mindset: Each participant is required to complete the self-evaluation with seventy-one items. Each item is evaluated between the scale of -2 for regressing badly and 2 for progressing considerably. It is observed that most of the participants reported that they progressed in terms of the design thinking mindset. Out of the twenty-eight participants, twenty-five evaluated that they progressed, while the other three evaluated regressed. The median and the mode for each of the items also indicated that the participants progressed in terms of the design thinking mindset. The highest min is for items D43 I find value in other people's diversity (perspectives, abilities), D54 I am comfortable to try new approaches to solve problems, and D64 I am curious about what I don't know. The lowest min, on the other hand, is for item: D7 I am comfortable in dealing with problems with which I cannot predict if they will be successfully solved

\section{LIMITATION OF RESEARCH}

The research was conducted with a limited sample size of twenty-five students. Initially, forty students signed up for the project, but the only $62.5 \%$ of the students followed through. Thirteen students $(32.5 \%)$ did not participate in the final workshop, and two students $(5 \%)$ did not even start the MOOC.

\section{CONCLUSION AND Future WORK}

1) Conclusion: The research sets out to determine the impact and factors of various evaluation. The evaluation triangle confirms that the independent review provides the most basic information. This is the first level of content evaluation. The assessments' submission evaluation and the feedback is at the same level. Both are providing input to details that cannot be observed through the independent review (see Fig. ??). Therefore, it is recommended to run a pilot for evaluation.

Secondly, the research aims to identify the impact of an online workshop on the MOOC. Not disappointing their peers is a motivation for completing the challenge. The majority of the students (64\%) are comfortable with having an online workshop. The students perceived that they grew in the design thinking mindset after completing the course and the workshop. Finally, contrary to the researcher's expectation, remuneration is not the primary motivation for completing the project. The main challenge is communicating online with group members.

2) Future Work: Initially, the online workshop compared who went through the MOOC and those who attended a twoday face-to-face workshop. However, it did not take place due to the Covid-19 situation. It will be interesting to evaluate if the face-to-face session, delivering the same content as the MOOC, may have different outcomes.

The social interaction and collaboration factor on MOOC can be further investigated. Students' openness towards online workshops supports integrating online workshops with MOOCs to increase interaction and collaboration. Another perspective to investigate what students meant by more collaboration opportunities when they do not even utilize comments or chat features.

\section{ACKNOWLEDGMENT}

We would like to thank Petrosains Malaysia for supporting this research.

\section{REFERENCES}

[1] M. Camacho, "David Kelley: From Design to Design Thinking at Stanford and IDEO," She Ji, vol. 2, no. 1, pp. 88-101, 2016. [Online]. Available: http://dx.doi.org/10.1016/j.sheji.2016.01.009

[2] D. Gamage, I. Perera, and S. Fernando, "Moocs lack interactivity and collaborativeness: Evaluating mooc platforms,' International Journal of Engineering Pedagogy (iJEP), vol. 10, no. 2, pp. 94-111, 2020.

[3] M. Marchisio and M. Sacchet, "Analysis items to assess the quality of open online courses for higher education," in International Conference E-Learning 2020. IADIS Press, 2020, pp. 63-70.

[4] C. Wrigley, G. Mosely, and M. Tomitsch, "Design thinking education: A comparison of massive open online courses," She Ji: The Journal of Design, Economics, and Innovation, vol. 4, no. 3, pp. 275 - 292, 2018. [Online]. Available: http://www.sciencedirect.com/science/article/pii/S2405872618300145

[5] C. Dosi, F. Rosati, and M. Vignoli, "Measuring design thinking mindset," Proceedings of International Design Conference, DESIGN, vol. 5, pp. 1991-2002, 2018.

[6] J. Kolko and R. Anderson, "On design thinking, business, the arts, STEM ...," Interactions, vol. 17, no. 2, p. 80, 2010.

[7] L. Corral and I. Fronza, "Design thinking and agile practices for software engineering an opportunity for innovation," SIGITE 2018 - Proceedings of the 19th Annual SIG Conference on Information Technology Education, pp. 26-31, 2018.

[8] W. Santos, C. Quarto, and L. Fonseca, "Study about software project management with design thinking," ACM International Conference Proceeding Series, 2018.

[9] F. Dobrigkeit and D. De Paula, "Design thinking in practice: Understanding manifestations of design thinking in software engineering," ESEC/FSE 2019 - Proceedings of the 2019 27th ACM Joint Meeting European Software Engineering Conference and Symposium on the Foundations of Software Engineering, pp. 1059-1069, 2019.

[10] A. L. Culén and A. Følstad, "Preface: Innovation in HCI- what can we learn from design thinking ?" Interaction Design and Architecture(s), vol. 27, no. 1, pp. 109-114, 2015.

[11] L. D. Grace and M. Farley, "How game design thinking becomes engagement design," AcademicMindtrek 2016 - Proceedings of the 20th International Academic Mindtrek Conference, pp. 281-286, 2016.

[12] A. Lugmayr, "Applying "design thinking" as a method for teaching in media education," Proceedings of the 15th International Academic MindTrek Conference: Envisioning Future Media Environments, MindTrek 2011, pp. 332-334, 2011.

[13] K. J. Schelle, E. Gubenko, R. Kreymer, C. Gomez Naranjo, D. Tetteroo, and I. A. Soute, "Increasing engagement in workshops: Designing a toolkit using lean design thinking," ACM International Conference Proceeding Series, vol. 29-30-Jun-, 2015.

[14] M. F. Chen, C. M. Yang, and W. Y. Lai, "Structured design thinking strategy in a collaborative context," SA 2016 - SIGGRAPH ASIA 2016 Symposium on Education, 2016. 